УДК 621.515

\title{
КОНЦЕПТУАЛЬНЫЕ ПОДХОДЫ К ОЦЕНКЕ РОЛИ И ЗНАЧЕНИЯ УПРАВЛЕНЧЕСКОГО УЧЕТА В СИСТЕМЕ ЭНЕРГЕТИЧЕСКОГО МЕНЕДЖМЕНТА
}

\author{
Н.А. САМОСЮК \\ магистр экономических наук, старший преподаватель кафедры «Экономика и организация энергетики» \\ Белорусский национальный технический университет, г. Минск
}

\section{Аннотация}

В статье автор рассматривает концептуальнье подходы и особенности использования управленческого учета в системе менеджмента организации. Выделяет общие черты и отличия финансового и управленческого учетов. Обосновывает ведение раздельного учета затрат по видам экономической деятельности в энергетике Республики Беларусь. Предлагает авторскую модель управленческого учета на предприятиях энергетики Республики Беларусь.

\section{Abstract}

The author examines the conceptual approaches and peculiarities of use management accounting in the management system of organization. He allocates common similarities and differences between the financial accounting and management accounting. He justifies the conducting of separate cost accounting through forms of economic activity in power engineering of the Republic of Belarus. He offers the author's model of management accounting in power engineering enterprises of the Republic of Belarus.

\section{ВВЕДЕНИЕ}

При существующей вертикально-интегрированной модели управления энергокомплексом Республики Беларусь, государство осуществляет централизованное регулирование финансовых отношений предприятий энергетики. Отсутствие рыночных механизмов регулирования в энергетике становится причиной снижения инвестиционной привлекательности многих видов экономической деятельности, высокие тарифы на энергоносители для промышленных потребителей сдерживают модернизацию предприятий и негативно влияют на их финансовое положение. Необходимо создание системы, учитывающей экономические интересы и производителей, и потребителей энергии, а так же создающей стимулы для экономии энергии на всех стадиях ее производства и потребления. Существующая система тарифообразования не дифференцирована по стадиям технологического цикла. Согласно положению №222 от 17.03.2014 г. о порядке формирования цен (тарифов) на природный и сжиженный газ, электрическую и тепловую энергию в Республике Беларусь формируется только базовый тариф на электрическую и тепловую энергию [1]. Социально-ориентированная экономика в Республике Беларусь нуждается в пересмотре тарифной политики, установлении цен на электрическую и тепловую энергию по видам экономической деятельности и по объектам производства на основании фактических затрат. Сложившаяся система учета не позволяет детально изучить затраты на каждом этапе производства электроэнергии. Поэтому для этих целей необходимо, параллельно с традиционным финансовым учетом, вести на предприятиях энергетической отрасли управленческий (раздельный) учет.

Значительный вклад в развитие теории формирования и управления затратами на современном предприятии внесли М.И. Баканов, А.А. Додонов, В.Ф. Палий, С.А. Стуков, А.Д. Шеремет. Сущность затрат, методы их планирования, учета и анализа, являющиеся частью системы управления, нашли свое отражение в трудах советских экономистов А.Ф. Аксененко, С.Б. Барнгольц, В.А. Бунимовича, В.И. Ганштака, А.Ш. Маргулиса, В.И. Петровой, И.И. Поклада, А.М. Фабричнова и др. Наиболее современный подход к проблеме изложен в работах А. Бочкарева, Т. Карповой, В. Кондратьева, С. Колесникова, С. Николаевой, В. Ткача, которые рассматривают управление затратами, как ядро системы управления организацией. Значительный вклад в развитие теории формирования и управления затратами в энергетике внесли Падалко Л.П., Нагорнов В.Н.

В настоящий момент вопросы реструктуризации в энергетике в основном рассматриваются с точки зрения макроэкономики. В тоже время, микроэкономический аспект реформирования энергетики и связанные с ним изменения в учете, контроле и управлении затратами не достаточно изучены. Это обуславливает необходимость разработки методики учета затрат в энергетике страны в условиях функционирования рынка энергии и мощности.

\section{РЕЗУЛЬТАТЫ И ИХ ОБСУЖДЕНИЕ}

Современная экономика характеризуется разнообразием видов экономической деятельности и может быть осуществлена на предприятиях различных организационно-правовых форм. Независимо от формы и сферы деятельности реализация функций бизнеса требует привлечения капитала для финансирования операций, определения объектов и объемов инвестирования полученных средств. Успех бизнеса зависит прямо от эффективного использования в процессе хозяйственных операций имеющихся ресурсов. Следовательно, любая предпринимательская деятельность состоит из трех взаимосвязанных элементов: инвестиционной, операционной и финансовой деятельности. Для согласования разных видов деятельности существует специфическая функция - управление. По мнению Н.И.Кабушкина, управление обеспечивает планирование, организацию, мотивацию, контроль и регулирование деятельности [2]. 
Планирование охватывает установление цели деятельности, определение необходимых ресурсов и путей достижения цели.

Достижение любой цели возможно только в случае эффективного труда персонала предприятия. Для достижения конечной цели бизнеса, необходимо таким образом организовать деятельность персонала, чтобы обеспечить гармоничную взаимосвязь между интересами бизнеса и коллективом работников. Принятие управленческих решений должно основываться на данных комплексного ретроспективного анализа и контроля, обеспечивающего сравнение достигнутых результатов с запланированными [3].

В случае выявления значительных расхождений необходимо осуществление процедуры регулирования, т.е. внесения соответствующих корректив в организацию производственного или технологического процесса или в систему бизнес-планирования - в зависимости от причин отклонения.

Для нормального выполнения рассмотренных функций управления необходима полная и исчерпывающая информация об объекте.

Для всех субъектов хозяйствования информация сегодня - это стратегический ресурс, который при рациональном использовании позволяет эффективно управлять бизнесом, расширять свою деятельность на рынке, улучшать экономические и финансовые показатели. Все это способствует росту ценности и спроса на информацию.

В настоящий момент, деятельность любого предприятия во многом зависит от его информационной сети. Высокая ликвидность и постоянная возобновляемость информации, с одной стороны, быстрое ее устаревание и возможность получить соответствующие данные аналитическим путем, с другой - вызывают определенные трудности в оперативном обеспечении управления достоверной, и свежей информацией.

Существует непосредственная связь между потоком информации и организацией производства. Информационный поток всегда подчинен целям и стратегии предприятия. Поэтому информацию должна представлять, прежде всего, система учета, которая выявляет и систематизирует данные о хозяйственной деятельности предприятия. Информационную систему, обеспечивающую потребности управления в информации, называют управленческим учетов.

Информация управленческого учета ориентирована на удовлетворение потребностей как стратегического, так и текущего управления, на оптимизацию использования ресурсов, обеспечение объективной оценки деятельности подразделений и отдельных менеджеров. Меняется назначение и наполняемость информации при плановой экономике и рыночной экономике. Традиционного финансового (бухгалтерского) учета не достаточно и возникает необходимость в управленческом учете.

Управленческий учет существенно отличается от традиционного финансового (бухгалтерского) учета, ориентированного на составление финансовой отчетности. Первое различие - это потребители информации. Финансовая отчетность предназначена, прежде всего, для внешних потребителей, однако используется и руководством предприятия.

Но для управления предприятием необходима более подробная информация, учитывающая технологию и организацию именно этого предприятия. Поэтому эта информация управленческого учета формируется и подается именно с учетом потребностей руководителей конкретного предприятия.

В отличие от финансового учета, который ведется с соблюдением определенных официальных регламентов (инструкций, стандартов и т.п.) установленных государственными органами или профессиональными организациями, управленческий учет не ограничен в выборе методов и правил. Его разрабатывает само предприятие с учетом разных параметров, учитывая при подготовке вариантов управленческих решений качественные факторы. Это так же отличает его от финансового учета, где все операции отражаются на счетах и в отчетности в едином денежном измерителе.

Финансовая отчетность отражает финансовое состояние и результаты деятельности предприятия за год или квартал. Такая отчетность не позволяет оценивать и анализировать деятельность отдельных подразделений и оперативно влиять на отклонение от запланированных параметров.

Поэтому в системе управленческого учета информация о деятельности отдельных сегментов (подразделений, филиалов, производственных линий и т.п.) готовится и предоставляется менеджерами в более сжатые промежутки времени (сутки, неделя, месяц), или по мере необходимости принятия решений.

Важной чертой, отличающей финансовый и управленческий учет, является направленность. Если финансовый учет описывает операции, уже имевшие место, то главной задачей управленческого учета является предвидение последствий будущих операций. Безусловно, в управленческом учете историческую информацию используют, но главным образом для контроля.

Наряду с различиями, управленческий и финансовый учет имеют так же и общие черты. Во-первых оба вида учета используют общую информационную систему, в частности данные учета затрат, используемые предприятием как для оценивания запасов и определения финансовых результатов, так и для принятия управленческих решений на разных стадиях и уровнях управления. Управленческий учет и отчетность являются базисом подготовки любой другой отчетности. Каждый из видов учета и отчетности имеет как общие с другими зоны, так и уникальные области учетной деятельности, присущие только ему. Во-вторых, данные финансового учета так же используют для принятия управленческих решений. В-третьих, оба вида учета базируются на концепции подотчетности менеджеров. При этом финансовый учет позволяет оценить результаты деятельности предприятия в целом, а управленческий учет - в рамках отдельных сегментов деятельности [4].

Информационный ресурс для составления отчетности общий как для финансового учета, так и для управленческого учета. Однако полученный информационный продукт различен у финансового и управленческого учета. На сегодняшний день традиционный информационный продукт финансового (бухгалтерского) учета энергопредприятия - 
фактическая себестоимость электрической энергии и фактическая себестоимость тепловой энергии учитывается обобщенно на счете 20 «Основное производство» [5].

Современная белорусская энергетическая система представляет собой сложный производственнотехнологический комплекс, включающий электростанции, котельные, электрические и тепловые сети, связанные общностью режима работы и единой системой диспетчерского управления. Установленная мощность энергоисточников ГПО «Белэнерго» на конец 2014 г.года составит 9446 МВт. Кроме того, параллельно с генерирующими источниками энергосистемы работают 183 блок-станции организаций, не входящих в состав ГПО «Белэнерго», мощностью 636 МВт. Установленная тепловая мощность энергоисточников энергосистемы составляет 47,3 тыс. Гкал/ч.

Электрическая сеть энергосистемы Республики Беларусь включает в себя линии электропередачи напряжением 0,4-750 кВ общей протяженностью 271773 км, трансформаторные подстанции напряжением $35-750$ кВ общей установленной мощностью 35019 МВА и трансформаторные подстанции 6-10/0,4 кВ общей установленной мощностью 16134 МВА. Протяженность тепловых сетей - 5 848,6 км в однотрубном исчислении.

По итогам работы за 2014 год энергоснабжающих организаций ГПО «Белэнерго» выработка электроэнергии составила 31,4 млрд кВт•ч, отпуск тепловой энергии - 34,0 млн Гкал.

Уровень развития и мощности отечественной энергетике позволяют удовлетворять растущие потребности потребителей в энергии и повышать качество жизни населения (таблица 1).

Таблица 1 Расход электрической энергии организациями Республики Беларусь по видам экономической деятельности

\begin{tabular}{|c|c|c|c|c|c|}
\hline Виды экономической деятельности & 2009 & 2010 & 2011 & 2012 & 2013 \\
\hline Израсходовано - всего & 29308 & 31701 & 31679 & 32065 & 31491 \\
\hline \multicolumn{6}{|l|}{ из него: } \\
\hline $\begin{array}{l}\text { сельское хозяйство, охота и лесное хо- } \\
\text { зяйство }\end{array}$ & 1531 & 1607 & 1609 & 1620 & 1660 \\
\hline горнодобывающая промышленность & 540 & 567 & 557 & 578 & 575 \\
\hline обрабатывающая промышленность & 12921 & 14640 & 15159 & 15108 & 14455 \\
\hline $\begin{array}{l}\text { производство и распределение электро- } \\
\text { энергии, газа и воды }\end{array}$ & 7263 & 7649 & 7222 & 7302 & 7253 \\
\hline строительство & 488 & 546 & 411 & 344 & 343 \\
\hline $\begin{array}{l}\text { торговля, ремонт автомобилей, бытовых } \\
\text { изделий и предметов личного пользова- } \\
\text { ния }\end{array}$ & 498 & 741 & 821 & 840 & 954 \\
\hline гостиницы и рестораны & 71 & 80 & 68 & 66 & 69 \\
\hline транспорт и связь & 1872 & 2022 & 2035 & 1964 & 1901 \\
\hline финансовая деятельность & 5 & 7 & 11 & 21 & 18 \\
\hline $\begin{array}{l}\text { операции с недвижимым имуществом, } \\
\text { аренда и предоставление услуг потреби- } \\
\text { телям }\end{array}$ & 627 & 648 & 584 & 442 & 451 \\
\hline государственное управление & 238 & 191 & 204 & 203 & 179 \\
\hline образование & 455 & 458 & 449 & 449 & 466 \\
\hline $\begin{array}{l}\text { здравоохранение и предоставление со- } \\
\text { циальных услуг }\end{array}$ & 265 & 272 & 268 & 265 & 260 \\
\hline $\begin{array}{l}\text { предоставление коммунальных, соци- } \\
\text { альных и персональных услуг }\end{array}$ & 187 & 239 & 314 & 305 & 309 \\
\hline
\end{tabular}

Энергетика производит около 30,0\% промышленной продукции страны, осваивает четвертую часть всех инвестиций в основной капитал промышленности, в ней сосредоточено 25\% основных производственных средств промышленности, занято более 5\% промышленно-производственного персонала.

В современных экономических условиях энергетика обеспечивает развитие предприятий национальной экономики, поэтому руководством страны и правительством особое внимании уделяется ее реформированию с целью создания адаптивной модели управления. Белорусская энергосистема требует реформирования, в результате которого должен быть создан реально работающий оптовый рынок энергии.

На первом этапе реформирования Белорусской энергосистемы предполагается осуществить переподчинение станций высокого давления. Электростанции высокого давления перейдут из подчинения РУП Оболэнерго в подчинение ГПО «Белэнерго». Это позволит достигнуть совершенствования системы управления за счет: централизации амортизационных отчислений и повышение эффективности их использования путем определения приоритетных направлений развития объектов генерации; более оперативного решения вопросов по расчетам за поставляемый на электростанции природный газ и др.

На втором этапе планируется выделение из состава областных энергоснабжающих организации филиалов «Энергонадзор» и создание на их базе Государственного учреждения «Энергонадзор». Совершенствование системы 
управления на данном этапе заключается в завершении процесса преобразования энергонадзора из ведомственного в государственный.

Третий этап включает в себя выделение из состава областных энергоснабжающих организаций высоковольтных электрических линий и трансформаторных подстанций напряжением 220-750 кВ, а также межгосударственных электрических линии и трансформаторных подстанций напряжением 10-110 кВ и передача их на баланс РУП «ОДУ», на базе которого будет создан РУП «Высоковольтные электрические сети» [6].

Формирование и последующее функционирование рынка потребует полного и достоверного учета затрат на всех технологических циклах генерации, передачи и распределения энергии для формирования обоснованного тарифа. Традиционный финансовый учет уже не может в полной мере обеспечить получение такой информации, поэтому возникает необходимость ведения раздельного учета затрат в энергетике.

Раздельный учет затрат по видам экономической деятельности в энергетике целесообразно осуществлять по следующим видам деятельности: генерация электроэнергии; передача электроэнергии; распределение электроэнергии; генерация теплоэнергии; передача и распределение теплоэнергии.

К объектам по производству электрической (тепловой) энергии относятся все генерирующие источники, независимо от установленной мощности: электростанции высокого давления, электростанции среднего давления и ТЭЦ малой мощности, генерирующие источники с использованием возобновляемых видов энергии и котельные. Калькуляционными единицами по видам экономической деятельности являются: по производству электрической энергии - 1 кВт•ч отпуска электроэнергии с шин источников электрической энергии; по производству тепловой энергии - 1 Гкал отпуска тепла с коллекторов источников тепловой энергии; по передаче электрической энергии - 1 кВт·ч отпуска электрической энергии из передающей электрической сети в распределительную электрическую сеть на границе их балансового разграничения; по распределению электроэнергии 1 кВт·ч валового отпуска электрической энергии; по передаче и распределению тепловой энергии - 1 Гкал валового отпуска тепловой энергии $[7,8]$.

Формирование учетных данных в подсистемах финансового и управленческого учета может происходить как обособленно, так и на основе их взаимодействия, как внутри единой системы бухгалтерского учета, так и без использования бухгалтерских процедур сбора и обобщения информации. Различие в целях управленческого и финансового учета, разнообразие методов сбора и обработки информации для управления не исключают необходимости установления информационной связи между видами учета по формируемым показателям о затратах и результатах деятельности предприятия. Зачастую операции, отражаемые в подсистемах финансового и управленческого учета, совпадают, что во многом обусловлено единством предмета и методологической основы формирования учетной информации на основе первичной документации, использованием одних и тех же измерителей и методов. Мировая и отечественная наука и практика свидетельствуют о том, что при построении системы счетов управленческого учета используется как монистический, так и дуалистический подходы $[9,10]$.

Монистический подход предполагает использование в финансовой и управленческой бухгалтерии единой (монистической) системы счетов (счета 20-29) и бухгалтерских записей. Дуалистический подход признает два независимых учета и опирается на двухкруговую систему отражения данных, в которой каждое направление учета имеет самостоятельную систему счетов и бухгалтерских записей (счета 30-39). Каждый из способов учета затрат имеет свои преимущества и недостатки. Поэтому при формировании системы учета затрат необходимо учитывать все технологические и производственные нюансы конкретного предприятия.

По нашему мнению, монистический подход к формированию системы счетов, наиболее привлекателен для бизнес-единиц, так как в этом случае используется один информационный ресурс. В этом случае затраты группируются по статьям, местам возникновения, а также для исчисления фактической себестоимости. Счета управленческого и бухгалтерского учета на уровне синтетических счетов совпадают, однако на уровне аналитических счетов уже имеют отличия.

Для формирования объективной информации о затратах в энергетике предлагается выполнить аналитическое расширение счета 20 «Основное производство», выделив субсчета по видам экономической деятельности (20.1-20.4); по объектам производства энергии; по объектам передачи энергии и по объектам распределения энергии. Это позволит не только получать детализированную информацию об объектах учета для целей контроля и регулирования деятельности, но и формировать консолидированную отчетность в целом по предприятию (на уровне РУП-облэнерго). Предлагаемая модель управленческого учета на предприятиях энергетики представлена рисунке 1 [11]. 
Экономическая наука сегодня №3

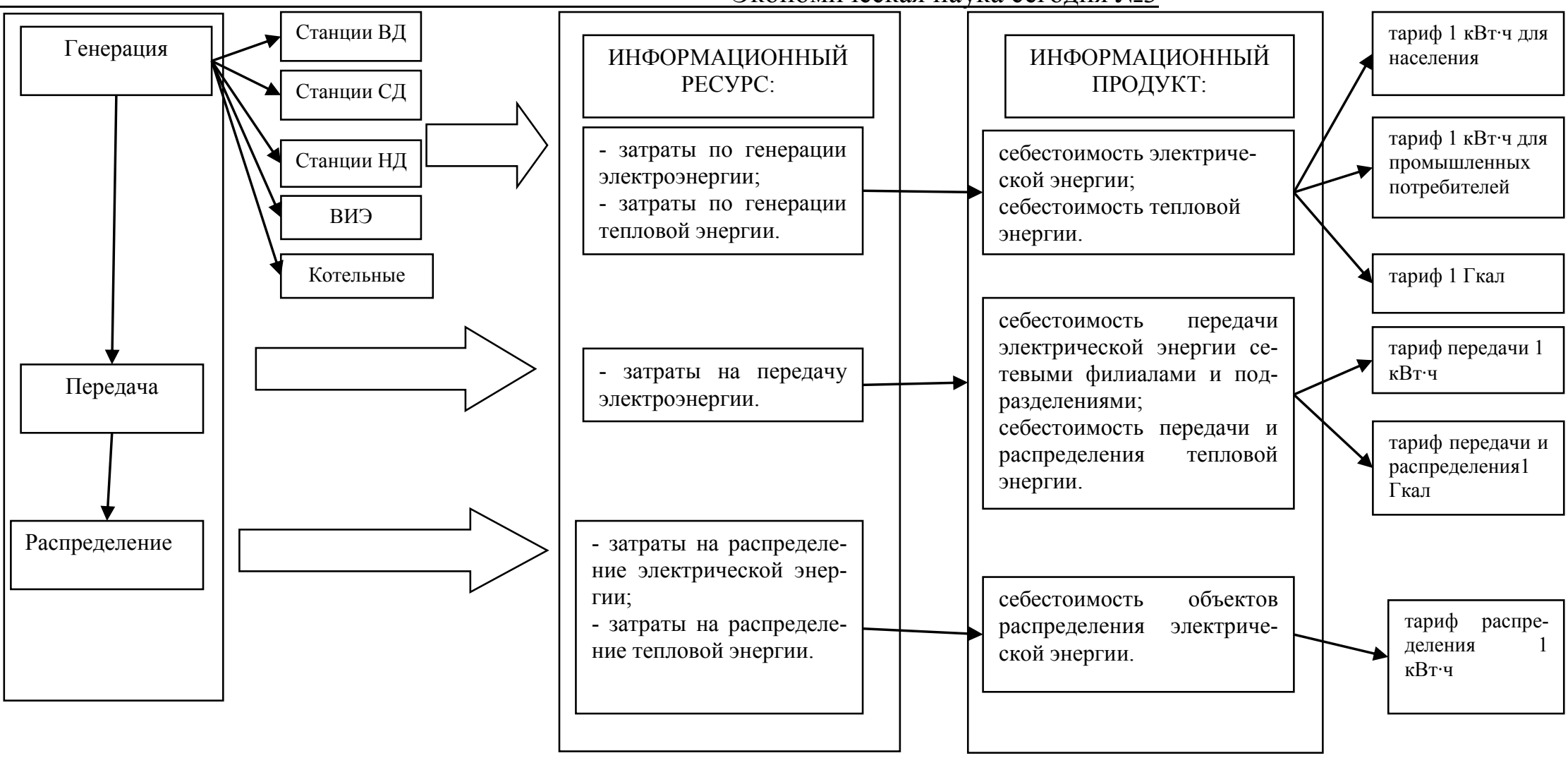

Рисунок 1 Предлагаемая модель управленческого учета на предприятиях энергетики 
ВЫВОдЫ

Внедрение управленческого учета на энергетических предприятиях республики будет способствовать получению информации необходимой для определения стратегии и планирования будущих операций организации; контроля ее текущей деятельности; оптимизации использования ресурсов; формирования обоснованного энерготарифа, оценки эффективности деятельности. В условиях рынка для целей управления затратами на предприятиях энергетики при использовании единого информационного ресурса возможно также применение и системы бенчмаркинга, который позволяет не только сравнивать показатели предприятия с показателями других организаций, но и использовать передовой опыт аналогичных предприятий.

\section{ЛИТЕРАТУРА}

1. Положение о порядке формирования цен (тарифов) на природный и сжиженный газ, электрическую и тепловую энергию (утверждено Постановлением Совета Министров Республики Беларусь 17.03.2014 №222).

2. Кабушкин Н.И. Основы менеджмента: Учебное пособие/Н.И. Кабушкин - Мн.: Новое знание, $2002-336$ с.

3. Голов С.Ф. Управленческий учет/ С.Ф. Голов.- Х.: Фактор, 2009- 784 с.;

4. Аверчев И.В. Управленческий учет и отчетность. Постановка и внедрение/ И.В. Аверчев. - М.: Рид Групп, 2011. $-416 \mathrm{c}$.

5. Сборник научных статей студентов, магистрантов, аспирантов/ Белорусский Государственный ун-т; под ред. В. Г. Шадурского. - Минск: Белорусский Государственный ун-т, 2015 г. - 258 с.

6. Государственное регулирование экономики и повышение эффективности деятельности субъектов хозяйствования: сб. науч. статей/Академия управления при Президенте; редкол.: С.А. Пелих [и др.]. - Минск: Академия управления при Президенте, 2014. - 352 с.

7. Инструкция по раздельному учету затрат на производство, передачу и распределение энергии в энергосберегающих организациях, входящих в состав государственного производственного объединения электроэнергетики «Белэнерго» утвержденной приказом ГПО «Белэнерго» 30 ноября 2013 г. №246

8. Государственное регулирование экономики и повышение эффективности деятельности субъектов хозяйствования: сб. науч. статей/Академия управления при Президенте; редкол.: И.И. Ганчерёнок [и др.]. - Минск: Академия управления при Президенте, 2015. - 195 с.

9. Курманова, А.Х. Варианты организации производственного учета/ А.Х. Курманова// Вестник Оренбургского государственного университета.- 2011. № 13 (132)

10. Курманова, А.Х. Методологические подходы к организации управленческого учета А.Х. Курманова// Вестник Оренбургского государственного университета.- 2012. № 13 (149).

11. 13-я Международная научно-техническая конференция «Наука - образованию, производству, экономике», Минск, 2015 г.: материалы конф./ Белорусский национальный технический ун-т; редкол.: Б.М. Хрусталев [и др.]. Минск, БНТУ, 2015.

Статья поступила в редакциюю 7 июля 2015 года. 